\title{
The development of a large Schools Management According the King's Philosophy Model
}

\author{
Phrapalad Somchai Payogo (Damnoen) ${ }^{1}$, Phumphakhawat Phumphongkhochasorn ${ }^{2}$, Rungroje \\ Songsraboon $^{3}$, Jitravee Thongtao ${ }^{4}$ \\ ${ }^{1}$ Mahachulalongkornrajavidyalaya University, \\ ${ }^{2}$ Eastern Institute of Technology Suvarnabhumi (EITS), Thailand \\ ${ }^{3,4}$ Siam University, Thailand. \\ Email:12n.2519@gmail.com, ${ }^{2}$ phumphakhawat.ps@gmail.com, ${ }^{3}$ rrs101@ @otmail.com, ${ }^{4}$ jitravee@yahoo.com
}

\begin{abstract}
This research aims to 1) study the elements of the development of a large school management model in accordance with the king's science, 2) develop a large school management model based on the monarchy, and 3) assess the suitability and appropriateness of the monarchy. The possibility of developing a large school management model according to the king's science By using a mixed method, a research was carried out in 4 steps: 1) study the elements of the development of a large school management model; 2) to develop a large school management model using the royal science Using the Delphi Technique and Focus Group Discussion, 3) analyzed the key elements through factor analysis and 4) assessing the feasibility and feasibility of the management model development. Manage a large school according to the king's science. From 30 school administrators, the statistics used for data analysis were percentage, range, quartile, mean, standard deviation, and component analysis. The research results were found as follows: 1) development of a large school management model according to the king's science is the management of the work with the middle line which consists of the philosophy of sufficiency economy and the principle of work of the king to achieve sustainable school development. $\quad$ 2) Develop a large school management model according to the king's science. There are 5 main components as follows: Sufficiency Economy Philosophy Understanding In terms of accessibility, development, and of the King's work principles.3) The degree of suitability and feasibility of the development of a large school management model according to the monarchy. Overall and each item are very good.
\end{abstract}

Keywords

development of management style; large schools; King's Philosophy

Article Received: 10 August 2020, Revised: 25 October 2020, Accepted: 18 November 2020

\section{Introduction}

The science of the king is the development of the King Rama IX with depth. All-round, foresight and emphasis on sustainability long before the global community becomes alert to this, it is a developmental approach aimed at improving the quality of life of all Thai people. Production, Research, Risk Management, Nature Conservation and Sufficiency Economy Philosophy, each element especially contributes to improving the quality of life of everyone. The poor and the needy by the experience of working that enables Thailand to go through various crises by working according to the king's science, understand, reach and develop as a method of the monarchy for sustainable development at His Majesty King Bhumibol Aduly. Dej has been used as a means of work throughout the reign of the king, has a very broad implication. Reliable, proven, His knowledge of the King has natural science, applied science, social science, anthropology, humanities, that is, all dimensions. If we follow / see the work that His Highness has worked for more than 70 years, $\mathrm{He}$ has made an example for you to see, all 1,500 places, all science, ethics, religion. The King places great importance on human development through education, both in the school system and outside the school, even the disadvantaged and remote places. Sustainable Besides, we must maintain a balance in both the economic and social dimensions. Another important aspect of the environmental dimension is to strengthen the foundation like a "pile", although no one sees it, may be forgotten, but it is a "primitive" structure that is very important to the overall structure. In this regard, to strengthen "Community", which is the foundation of that country, King Rama IX insisted that the first lesson was "Let the villagers be teachers" centered on people, emphasizing "inner explosions", not just external impacts. (Krerati, 2005)

Basic education core curriculum, B.E. 2008, which adheres to the philosophy of sufficiency economy as one of the five goals of the curriculum, has developed the quality of learning about the sufficiency economy philosophy. As well as the development of the school to be assessed through a sufficiency educational institution, content framework for organizing learning activities. Sufficiency Economy Philosophy Consists of the principle of modesty they are rational and have a good familiarity on the basis of two conditions: the use of knowledge, prudence, vigilance and morality to prepare for the change in material, social, environmental and cultural aspects. The Sufficiency Economy Philosophy has been the guiding philosophy in formulating the National Strategy (20 years) as well as the National Economic and Social Development Plan No. 12 2017-2021, with a focus on leading to sustainable development practices, in which the philosophy of sufficiency economy will be a development path that leads to sustainability, the internal strength must be strengthened before starting. From self-reliance, self-reliance and vigorous integration and understanding of future development paths, there is a quality growth in line with the 
nature of "Thai 4.0". The monarchy of the Philosophy of Sufficiency Economy and the Sustainable Development Goals (Ministry of Education, 2009).

The 20-Year National Education Plan (2017-2036) is a strategic plan to formulate an Action Plan (Action Plan) to serve as a guideline for continuing education for target groups of all ages, from pre-primary, early childhood levels Primary, secondary, vocational and vocational education and working age by working integrally within the Ministry of Education and integrating with relevant departments, the National Education Plan is the heart of the Bible in working together to adjust the national education plan. To be consistent with and support the national strategy 20 years of emphasis on education management covering all age groups according to the constitution. There are 6 strategies for working together with cooperation, focusing on practical training to create a leadership group to drive the country Vision All Thais receive education and learn throughout their lives with quality. Live a happy life in line with the Philosophy of Sufficiency Economy and Global Change in the 21st Century (Ministry of Education, 2009).

The 12th Educational Development Plan of the Ministry of Education (2017-2021) addresses a new mechanism in "human development" that is the country's most important resource. This is the reason for the need for the 12th edition of the Education Development Plan (2017-2021) for use as a master plan in setting goals and directions of the Ministry of Education's mission operations and the government agencies in accordance with the direction of national development in the next 5 years to develop Thailand to stability. Prosperous and sustainable To happen in the future Must give priority to strengthening the existing national capital They are powerful enough to drive the medium and long term development process, especially "human development" to prepare them for the changes in the world in the 21 st century, the most important of which is cognitive skills. And enhancing environmental factors contributing to the development of quality of people By embracing the philosophy of Sufficiency Economy of King Bhumibol Adulyadej Come and apply Both systems and structures of Thai society to have protection against various changes that will occur (Jukparun, 2012)

At present, the school is the main unit and the closest practice unit to the learner in order to act for the reform of education in accordance with the spirit of the National Education Act of Thailand. In 1999, the goal of achieving quality students, receiving comprehensive, equitable and fair educational services, therefore, and educational institutions must have effective and efficient administration, capable of supporting the decentralization, administration and management of education from the state. Indeed, both academic administration, budget management, personnel administration and general administration, but on the other hand, such policies are often criticized for increasing injustice and inequality in the education system. Create burdens and costs on stakeholders in disadvantaged areas, for example, students may have to leave school, parents face higher expenses, etc.

The way for the development of large school management is a new concept that will truly help the development of large school management to be successful, which is the application of the "royal science" in quality management.
Education in which "The King's Philosophy" is a practice that demonstrates understanding, access and development as a method of the monarchy for sustainable development that His Majesty King Bhumibol Adulyadej reigns. 9 Having been used as a working method throughout the reign, the researcher was interested in applying the king's science in the area of school administration according to the philosophy of Sufficiency economy in 5 areas, which consisted of education administration, curriculum and learning management. Taught the organization of learner development activities, personnel development of educational institutions, and results / images of success understanding (Understanding) consist of 4 elements: use of existing data (Existing data) Use of empirical data. Data), Analytics and Research and Experiment till actionable results (Connecting) consist of 3 sub-components. Is an explosion from inside (Inside-out blasting, Understand target, and Educate. Development consists of 3 subelements: self-initiated, self-reliance and 3. A model for disseminating knowledge. (Prototype and role model) to be used in "the development of large school management according to the king's science" to raise the educational quality of small schools to higher in steadfastness, prosperity and sustainability

\section{Research Objectives}

1. To study the elements of the development of large school management according to the king's science model.

2. To create a model for the development of large school management according to the king's science

3. To assess the feasibility and feasibility of a large school management development model according to the king's science.

\section{Research method}

Step 1 Study the concepts, theories, texts, documents and research related to the development of large-scale school management based on the king's science model.

Step 2 Do the Delphi Technique Create an expert interview. To get opinions with the Delphi technique process using a specific selection method to find consistency from opinions of 11 experts, the qualifications of the experts are People with knowledge and ability to develop large-scale school management according to the royal science.

Step 3: Focus Group Discussion by inviting 13 school management experts and related people to participate in a group discussion on the development of a large school management based on the royal style.

Step 4 Evaluation: When the three-step process is completed, the researcher will use the results as a rating scale questionnaire for large school administrators. Under the Office of Chonburi

Educational Service Area, Region 1-3, 60 people voted to comment one more time to make the model more complete. 


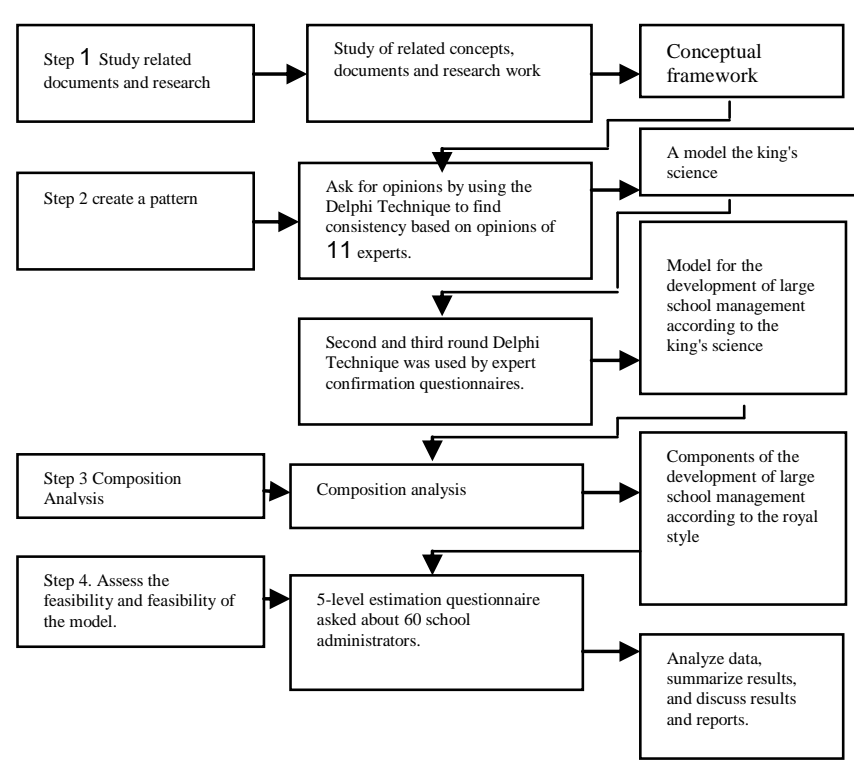

\section{Sample selection}

\section{Population for the Delphi technique}

The research population was the school administrators. Educational Administration Qualifications Academic of Educational Administration with a track record in school administration in the King's leadership. Or schools that have received awards such as the school award sufficiency Economy Learning Center Award

The sample group used in this research was education administration personnel. Academic in education administration and school administrators using a specific selection method of 30 people, based on their qualifications, experience in school administration. And is famous in the education industry

2. Population for inquiring using questionnaires

The population for questionnaire was used by the school administrators of 60 schools.

The sample group for answering the questionnaire was the administrators of large schools under the Chonburi Primary Education Area Office 1-3 by using the method of opening the tables of Crazy and Morgan (Krejcie \& Morgan, 1970) has a sample. Large educational establishments, 30 schools, one student each school by sampling.

\section{Construction and development of research tools}

Research instruments

1. The interview form is an open-ended, unstructured question about the management of a large school according to the king's science, divided into 3 parts:

Part 1 General information of the interviewee

Part 2 Components for the development of large school management according to the royal style Part 3 Other Suggestions

2. Opinion questionnaire, evaluation form 5 levels (Rating Scale) on the development of large school management according to the royal science model it is divided into 3 episodes which are

Part 1 General information of respondents
Part 2 Components of the development of a large school management based on the monarchy form obtained from interviews with 100 experts.

Part 3 Other Suggestions

\section{Tool construction process}

Part 1 is an open-ended, unstructured question about the development of a large school management based on the king's science model. By studying the concepts and theories about school administration Concepts and theories about the science of the monarchy Concepts and theories about administration of educational institutions; Basic concepts of large school administration and related research work.

1. To be used as information in determining the scope and content of the interview.

2. Analyze variables and issues to study to set as question in the interview

3. Create an unstructured interview form from conclusions drawn from the analysis of concepts, theories and related research. For interviewing school administrators Expert Academic of Educational Administration

4. Take the completed interview. Offer an adviser to check

5. Revise the interview form. According to the advice of an advisor

6. Bring the revised interview form. To interview 11 experts for Round 1

7. Bring the interview form for each expert to confirm the accuracy from the second interview.

8. Take data from interviews of 13 experts in the second round to use content analysis and ask the experts to answer questions in the third round by doing a 5-level rating questionnaire (Rating Scale) using the rating scale of Liket according to the following criteria:

A score of 5 means that opinion is the highest.

Weight score of 4 means there is a high level of opinion.

Weight score of 3 means there was a moderate level of opinion.

Weight score of 2 means there is little opinion.

A score of 1 means that opinion is the least level.

This is to analyze the median, mode, and interquartile range to create a new questionnaire. To inquire about 60 large school administrators

Part 2 Comment Questionnaire 5-level evaluation form (Rating Scale)

1. Bring the completed questionnaire in item 8 to the advisor to check the accuracy and initial suitability.

2. Revise the questionnaire according to the advice of the advisor then brought to the experts for 5 persons to check to test the content validity and to find the index of conformity or IOC (Index of Item Objective Congruence) and consider choosing questions that have more IOC. 0.50 And above are 100 items of income questionnaire

3. Revise the questionnaire. Based on expert suggestions and recommendations of advisor

4. Take the revised questionnaire to tryout with the administrators of large schools, Kamphaeng Phet Province. Which were similar and not a sample used in this research, 30 people to analyze the accuracy. (Reliability) by using the alpha coefficient. (Alpha-Coefficient) by setting the confidence value of the whole questionnaire. Must have a value of 0.70 or more (Boonchom, 2002) 
5. Tryout questionnaires were used to collect data from 30 large schools, one student per school, and analyzed the data by using a random sampling program.

\section{Data collection}

Procedures for collecting information from the interview.

1.1 Submit a letter requesting assistance to collect information To give details before proceeding to the interview

1.2 The researcher used the interview method by traveling to interview by himself.

1.3 Send a thank you letter Interview specialists who provide information on educational institution management.

2. Procedures for collecting data from questionnaires

2.1 Investigators follow up and collect data for each school setting.

2.2 Introduce the self-introduction letter and a questionnaire asking for help in answering the questionnaire for the sample group of 30 schools administrators, 1 person per school Each educational institution, the researcher collects questionnaires by themselves. And some places sent by post In addition, there are some places that collect information online, where the researcher takes the completed questionnaire to create a form on google drive and then sends a link to request cooperation from the sample group to fill in the information online ready to request a convenient date on Receiving questionnaires

2.3 Researcher collects questionnaires at appointed time to check the completeness of questionnaires. And send a thank you letter which the researcher received the questionnaire back from the sample $100 \%$

\section{Data analysis}

1. Analysis of information from the interview. 1.1 Information obtained from the interview Use content analysis

2. Analysis of data from questionnaires

2.1 General information of the respondents was analyzed by using quantitative statistics such as Frequency and Percentage.

2.2 Information on the elements of large school management according to the king's science the researcher analyzes the data by using a package program by distributing the frequency. And find the percentage in the selected part using the mean And the standard deviation in the approximate scale portion To determine the average score for each level, the criteria are as follows (Boonchom, 2002).

The average score of 4.50-5.00, meaning that is most suitable.

The average score of 3.50-4.49 means that the suitability is at a high level.

The mean score of 2.50-3.49 means that the suitability is in the medium level.

The average score of $1.50-2.49$ means suitability is at a low level.

The average score of $1.00-1.49$ means that the suitability is the least.

2.3 Analysis of the data obtained from expert interviews is the second and third round questionnaires used to calculate the median, mode, and interquartile range. (Interquartile Range) using a program

\section{Research findings}

Objective 2. The research found that the creation of a large school management development model according to the king's science model Using the Delphi Technique from interviews with 11 experts, questions were analyzed from the Delphi Technique Round 1 and the Delphi Technique in Round 2 and Round 3 to verify authenticity from experts Focus Group Discussion by 13 school management experts to seek advice and recommendations in accordance with the format. And exploratory factor analysis to examine the weight values of the indicators for each component. The criteria for selection were factor loading of 0.5 and above. There are 5 main components as follows: 1) The Sufficiency Economy Philosophy consists of 8 indicators. The factor loading factor was between $.898-.547$, the variance was 8.87 and the percentage variance was 7.141. 2). It consisted of eight indicators, with a factor loading of .887 - .624, a variance of 7.14 and a percentage of variance of 6.88753 ) accessibility. It consisted of 6 indicators with a factor loading factor between $.657-.535$ and a variance of 5.6554 and a percentage of variance of 5.3544 ). There were six indicators, the factor loading factor was between $.835-.534$, the variance was 4.24 , and the percentage variance was 3.34 and 5). Of the king It consisted of eight indicators with a factor loading factor of $.734-.5145$, a variance of 3.547 and a percentage of variance of 2.424 , respectively. 1 . The research results showed that the development of large school management in accordance with the king's style is the central management system consisting of The Sufficiency Economy Philosophy consists of curriculum and 
instructional management, educational administration, learner development activities, educational institution personnel development, and results or images of success and performance principles. The kings there are two components: Understanding and development in order to create a model for sustainable development of the royal school

Objective 2. The research found that The creation of a large school management development model according to the king's science model Using the Delphi Technique from interviews with 11 experts, questions were analyzed from the Delphi Technique Round 1 and the Delphi Technique in Round 2 and Round 3 to verify authenticity from experts Focus Group Discussion by 13 school management experts to seek advice and recommendations in accordance with the format. And exploratory factor analysis to examine the weight values of the indicators for each component. The criteria for selection were factor loading of 0.5 and above. There are 5 main components as follows: 1) The Sufficiency Economy Philosophy consists of 8 indicators. The factor loading factor was between $.898-.547$, the variance was 8.87 and the percentage variance was 7.141.2). It consisted of eight indicators, with a factor loading of .887-.624, a variance of 7.14 and a percentage of variance of 6.88753 ) accessibility. It consisted of 6 indicators with a factor loading factor between $.657-.535$ and a variance of 5.6554 and a percentage of variance of 5.3544 ). There were six indicators, the factor loading factor was between $.835-.534$, the variance was 4.24 , and the percentage variance was 3.34 and 5). Of the king It consisted of eight indicators with a factor loading factor of $.734-.5145$, a variance of 3.547 and a percentage of variance of 2.424 , respectively.

Objective 3. The research results were found that The results of the feasibility and feasibility assessment of the large school management development model based on the monarchy model From 30 large school administrators under the ChonBuri Educational Service Area Office 1-3, it was found that the level of suitability and feasibility of the large school management development model according to the king's science model. Overall and each aspect Very good the average value can be sorted from descending as follows: Work principles $(\bar{X}=4.91, \mathrm{SD}=0.87)$ : 1$)$ The school adjusts the teaching plan to be simple, uncomplicated, and 2) the school has a modern administrative system. By adhering to the principles of accuracy, speed, economy, value. 3) School administrators manage with fairness. Using the rule of law Philosophy of Sufficiency Economy 4) the school instills students to adhere to honesty and sincerity to each other. 5) The school provides teaching and learning that focuses on students to learn happily $(\bar{X}=4.78 \mathrm{SD}=$ $0.65)$, namely 1) measurement and evaluation. Learning activities According to the philosophy of sufficiency economy 2) media and learning resources About the philosophy of sufficiency economy 3) Personnel development according to the philosophy of sufficiency economy 4) Integration of the economic philosophy Sufficiency for learning activities 5) Provide guidance activities for learners to plan their own life. In line with the philosophy of sufficiency economy and 6) organizing guidance activities and a system to take care of helping learners According to the Sufficiency Economy Philosophy
$(\bar{X}=4.57, \quad$ SD $=0.68)$, namely 1$)$ the students have knowledge and understanding of the secrets of the sufficiency economy philosophy. In accordance with the learning standards of the sufficiency economy of each level in the academic year. Understanding and realizing the value of the philosophy of sufficiency economy 3) organizing meetings, training seminars, study visits to various learning sources. To strengthen the application of the sufficiency economy philosophy in Live and perform duties 4) Learners are involved in problem solving. Or developing a community school in an economic or social or environmental or cultural environment In accordance with the philosophy of sufficiency economy 5) organize activities to promote life and performance According to the philosophy of sufficiency economy for educational personnel In terms of accessibility ( $\bar{X}=4.76, \mathrm{SD}=0.345$ ), namely 1) executives can direct personnel goals to adapt to the needs and goals of the organization 2) learners practice themselves Live a balanced life 3) Personnel can live with cultural foundations and are ready to embrace social changes. Cultural transformation from globalization 4) Executives provide opportunities for personnel to discuss career goals with people who can offer good opportunities; and 5) Executives propose factors that help people be successful in their work. Work And understanding ( $\bar{X}=$ $4.72, \mathrm{SD}=0.43$ ), namely 1 ) the school developed classroom research to improve the student's teaching and learning 2) The school used data to analyze the program 3) The school developed an information network system. Modern 4) The school has organized a record system, reporting results and transferring student information, 5) the school uses learning resources and local wisdom for teaching and 6) the school promotes research to develop learning. Follow up and use the results to develop learners to their full potential accordingly.

\section{Discussion}

The results from the objective research item 1 showed that the development of large school management according to the royal science model Is the management of the work with the middle line Which consists of The Philosophy of Sufficiency Economy and the King's work principle is "Understanding and Development" to achieve sustainable school development. Which the education of learners in each level from the early childhood level Basic education level Vocational level Tertiary level Professional level And the level of the elderly will have different goals than before, with respect to all dignity. The situation with the slowdown, the progression, or the gratitude that has occurred is the learner has a reason. Do not underestimate, think, analyze, solve problems and lead to life (Chutima Watthana Khiri, 2018: online) is the basis for living according to principles.Sufficiency economy is planned for living. There is a purpose of self-sufficiency in four factors. There is a reason to act, able to control their own income and expenditures, in fact, have to withhold excess spending. Have knowledge and intelligence according to the level of the person according to the age range the problem must be analyzed and the problem can be solved. There is a positive change, not clinging to what is wrong, not suitable. Devise a method for self-development in a correct way Continuous 
self-improvement in the correct use of one's own and national resources based on the 6 dimensions of knowledge, consciousness, and love of nature / environment. Coexist with others in a helping hand without hurting each other Have pride and see the value of Culture, values, identity of being Thai At the vocational and tertiary education level there must be an education that enhances the identity of learners in the immunization professional field. Creative career sufficient living Avoid the deceitfulness the school has a sufficient economy learning resource to implement a career building project. There is a profit-loss account. Income-expenditure, study, research, practice, and network with the community

The results of the objective research item 2 found that the large school management development model according to the king's science model there are 5 main elements which are the philosophy of sufficiency economy. Understanding In terms of accessibility, development, and of the King's work principles this is because administrators have a good understanding of knowledge management activities for use in management. Executives have leadership in driving projects in accordance with objectives. The school has good relationships with the local community and the community. And have learning resources on the sufficiency economy both inside and outside the school who is the teacher Not that there will only be knowledge in academics and in teaching. Must know how to train children both in morality and culture As well as to have a sense of responsibility in their duties and in the capacity to be a good citizen of the nation in the future Educating knowledge, also known as teaching, is different from training. Teaching is to educate the learners while the training is to train the mind of the learner to become a habit. May you not only teach, to train to acquire such knowledge, you can see that the purpose of the education of all levels of the people is essential to the cognitive domain, the psyche (Affective Domain) and practical aspects (Performance) This is in line with Preecha Chang Kwan Yuen and the team (2013) Khiri Boon Jongwuttiwet and Mariam Nilpan (1999) and the Government System Development Committee (2008) that discussed the characteristics of the good manual. That good guide it must state the importance and benefit of the manual that will apply to those concerned. The purpose of using the manual is clearly defined for what the researcher will get, and clarifications for relevant persons to know and understand the process.Using the manual to make the book interesting the contents of this manual should be suitable for the knowledge base of the person who will be studying and use language that is easy to understand. Examples are available for easy understanding, illustrated and updated.

The results from objective research 3, it was found that the degree of feasibility and feasibility of the large school management development model according to the monarchy model. Overall and each aspect Very good since the administrators have knowledge and understanding of knowledge management activities to be used in the management, the executives have the leadership to drive projects in accordance with the objectives. The school has good relationships with the local community and the community. And there are learning resources on the sufficiency economy both inside and outside the school for a variety of processes. Thus causing the large school management level according to the king's science Overall and each item Very good Consistent with the research of Wongchan Kaew Si Nuan (2014) conducted research on Development of the school's academic administration manual to expand educational opportunities Under the Office of Surat Thani Primary Educational Service Area 1, it was found that the results of expert evaluation Is suitable at the highest level

\section{Suggestions for the next research}

From the research on the model for the development of large school management according to the king's science model Researchers have seen the benefits that will be used in the development of schools to develop large-scale school management to sustainable development under the Office of Chonburi Educational Service Area, District 1-3, as follows. 1. The Office of the Basic Education Commission and the Chonburi Educational Service Area Office, District 1-3, should take the research results into consideration to be used as a guideline for monitoring the performance in each area to ensure consistency and coordination. Between departments to be done quickly

2. The Office of the Basic Education Commission and the Chonburi Educational Service Area Office, District 1-3, should take the research results into consideration to be used as a guideline for organizing training to provide opportunities for school directors, teachers and personnel. In the future, education has increased their knowledge and understanding about other areas of school management development operations.

\section{References}

[1] Boonchom S. (2002). Preliminary research. Bangkok: Suwiriyasat.

[2] Jukparun W. (2012). Development of basic education institution management model according to the philosophy of sufficiency economy. Chiang Mai: Faculty of Education, Chiang Mai Rajabhat University.

[3] Krejcie, R. V. \& Morgan, D. W. (1970). Determining Sample Size for Research Activities. Educational and Psychological Measurement, 30(3), pp. 607-610.

[4] Krerati Y. (2005). Knowledge management in organizations and case studies. Bangkok came to see the city. Mr. Copy.

[5] Ministry of Education. (2009). Guidelines for bringing sufficiency economy philosophy to education in schools, the 
sufficiency economy research project. Bangkok: The Crown Property Bureau.

[6] Preeyada S. and Samrech Y. (2012). Learning management according to the philosophy of sufficiency economy in schools under the Office of Secondary Educational Service Area 25. Khon Kaen: Office of Educational Service Area 25.

[7] Kamthon Sinthavanont. (1996). Thinking King. Bangkok: Amarin Book Center.

[8] Disnadda Diskul. Mom Ratchawong. (2012). From the King's science to sustainable Thai development. (Online). AccessFromhttps://www.matichon.co.th/ec onomy/eco-report/news_1067811

[9] Thawanrat Worathep Puttipong. (1997). Formulation and Analysis of Public Policy: Theory andApplied. Bangkok: Sema Tham.

[10] Thepparatratsuda Siam Boromrajakumari Somdej Phra. (2012). Royal speech. (Online). Accessed from http://www.manpattanalibrary.com/newsd etail.php?id=23Prayut Chan-o-cha. (2016). the King's Science towards Sustainable Development. (Online). Access from http://nwnt.prd.go.th/CenterWeb/News/Sp ecialNewsList?NT22_TmpID=TM591021 02

[11] Suchanya Mueng Klang. (2018). the results of the reform of the supervision, understand, access, and develop in the field of mathematics learning management. Ban Moon Songkhro School Kalasin Primary Educational Service Area Office: District 1. Kalasin:

[12] Sumet Tantivejkul. (2014). Follow in the footsteps of the King Teacher of the land. Edition 2. Bangkok: Chulalongkorn University.

[13] Eisner,E. (1976). "Education Connoisse urs hip and Criticism their from and Functions in Educational Evaluation" Journal of Aesthetic Education.P.192-193.

[14] Eisner,E. (1976). "Education Connoisse urs hip and Criticism their from and Functions in Educational Evaluation" .Journal of Aesthetic Education.192-193. 